\title{
O DeVir-Deficiente da Pedagogia: Notas Para Uma Antropologia
}

\author{
Filosófico-Educacional da Plasticidade
}

\author{
Alexandre Simão Freitas ${ }^{1}$ \\ Universidade Federal de Pernambuco - UFPE
}

\section{Resumo}

Esse ensaio problematiza os processos formativos enquanto processos antropotécnicos, almejando contribuir com o debate acerca dos sentidos imanentes aos discursos que visam promover e difundir múltiplos aparatos para inclusão das diferenças. $\mathrm{O}$ argumento central defende que o abandono da reflexão em torno da noção de plasticidade tem privado a filosofia da educação de pensar os processos de exposição das vidas que não se deixam dobrar aos códigos normativos vigentes, ocultando um possível devir-deficiente da própria pedagogia. O devir-deficiente da pedagogia passa pelas manifestações expressivas das formas que explodem e que se fazem catástrofe. A plasticidade configura-se então como condição de possibilidade e como uma ameaça aos humanismos domesticadores. Seguindo as reflexões de Peter Sloterdijk e Catherine Malabou, a plasticidade é pensada como um indicativo de que toda vida humana se constitui como um acidente incontornável, sendo a deficiência apenas um limite nas tentativas biopolíticas de reconstituir um modelo ideal ou totalizante do humano. Assim, os deficientes podem guardar algumas lições inquietantes acerca de nossas máximas pedagógicas, apontando uma disposição ético-política para pensar a formação humana para além da noção de perfectibilidade. Dessa ótica, o devir-deficiente da pedagogia pode colocar em questão os arcanos quase esotéricos da reflexão pedagógica ocidental.

Palavras-chave: devir-deficiente; plasticidade; antropotécnicas; formação humana.

\section{The Becoming-Deficient Pedagogy: Notes For Anthropology Philosophical- EDUCATIONAL OF PLASTICITY}

\begin{abstract}
This essay discusses the formative processes while antropotechnic processes. The expectation is to contribute for the debate about the meanings inherent in speeches that promote and disseminate multiple devices for inclusion of differences. The central argument defends that the abandonment of reflection on the notion of plasticity has deprived the philosophy of education to think the exposure processes of lives that do not allow themselves to double the existing normative codes, hiding a possible becomingdeficient's own pedagogy. The becoming-deficient pedagogy goes through expressive manifestations of the life forms that explode and are made disaster. Plasticity is configured so as a condition of possibility and as a threat to domesticating humanism. Following the reflections of Peter Sloterdijk and Catherine Malabou, plasticity is thought of as an indication that all human life is an unavoidable accident, and disability only a limit on biopolitics attempts to reconstruct an ideal or totalizing model of the human. Disabled people can save some disturbing lessons about our pedagogical maxims. The becoming-deficient pedagogy points an ethical-political will to think about human
\end{abstract}

\footnotetext{
${ }^{1}$ E-mail: alexshiva@uol.com.br
} 
o devir-deficiente da pedagogia: notas para uma antropologia filosófico-educacional da plasticidade

development beyond the notion of perfectibility, jeopardizing one of the esoteric secrets of Western pedagogical reflection.

Keywords: becoming-deficient; plasticity; antropotechnic; human formation.

\section{El DeVENiR-Discapacitado de la Pedagogia: ObSerVaciones Sobre la ANTROPOlOGía-FILOSÓFICA-EDUCATIVA DE LA PLASTICIDAD}

\section{Resumen}

Este ensayo analiza no solo los procesos formativos, sino los procesos antropotécnicos. Por tanto, se espera que contribuya al debate sobre el sentido inmanente de los discursos de promoción y difusión de múltiples dispositivos para la inclusión de las diferencias. El argumento central sostiene que el abandono de la reflexión sobre la noción de plasticidad ha privado a la filosofía contemporánea de la educación de pensar que los procesos de exposición de vidas que no se dejan vencer por los códigos normativos existentes, ocultando un posible devenir-discapacitado de la propia pedagogía. El devenirdiscapacitado de la pedagogía pasa por las manifestaciones expresivas de las formas que estallan y se hacen pedazos. La plasticidad se configura como una condición de posibilidad y como una amenaza para los humanismos domesticadores. Siguiendo las reflexiones de Peter Sloterdijk y Catherine Malabou, se cree que la plasticidad ofrece una indicación de que toda vida humana es un accidente inevitable, y la discapacidad un límite de la biopolítica que trata de reconstruir un modelo ideal de lo humano. Las personas con discapacidad pueden guardar algunas lecciones inquietantes sobre nuestras directrices pedagógicas. La deficiencia señala una voluntad ético-político para pensar en el desarrollo humano más allá de la noción de perfectibilidad, poniendo en peligro uno de los secretos esotéricos de la reflexión pedagógica occidental.

Palavras-chave: devenir-discapacitado; plasticidade; antropotécnica; formación humana. 


\section{O Devir-Deficiente da Pedagogia: Notas Para Uma Antropologia Filosófico-Educacional da Plasticidade}

\section{Introdução}

Na origem era a ruína. Jacques Derrida

Nosso século se abriu sob um forte sinal de alerta quanto aos perigos desdobrados seja pela destruição das barreiras metafísicas erguidas entre os seres vivos, seja pela difusão de modelos biotecnológicos que propõem sua reconstrução. Parece não haver dúvidas que está em curso uma apropriação política e econômica da vida. Vida precária, vida nua, vida besta (BUTLER, 2009; AGAMBEN, 2008; GIORGI, 2016) são apenas algumas das expressões mobilizadas para descrever a sobrevalorização do princípio de preservação da vida, o qual parece exigir que sociedades e governos passem a lutar tenazmente para que vidas inviáveis sejam salvas, vidas doentes sejam curadas ou prolongadas e vidas hipotéticas sejam criadas com base em uma espécie de valor-vida².

Tudo indica que estamos diante de novas formas de biossocialidade associadas ao advento de uma economia bio-fármaco-molecular generalizada que circunscreve os modos de produção, consumo e circulação da vida-capital (ROSE, 2013; PRECIADO, 2008; PELBART, 2013). Nesse contexto, os indivíduos passam a compreender a si mesmos como cidadãos biológicos, quer dizer, como sujeitos portadores de direitos e deveres, cujas formas de interação têm como horizonte de inteligibilidade a possibilidade mesma de modificação e reconfiguração das suas vidas. Assim, o desenvolvimento de tecnologias voltadas para o replanejamento da vitalidade modifica antigas dicotomias como natureza-cultura, corpo-mente, real-artificial, normal-patológico, abrindo dinâmicas de intervenção e escolha que

\footnotetext{
2 O novo princípio de preservação da vida, exemplificado de forma paradigmática, no chamado culto da performance, não busca simplesmente curar danos orgânicos, nem incrementar a saúde. Ao contrário, descolando-se dos regimes dietéticos clássicos, o que se almeja é intervir nos próprios processos vitais, a fim de maximizar seu funcionamento e incrementar seus resultados (EHRENBERG, 2010, p. 176).
} 
o devir-deficiente da pedagogia: notas para uma antropologia filosófico-educacional da plasticidade

parecem ameaçar os próprios limites traçados pelo princípio da inviolabilidade da natureza humana (HABERMAS, 2003).

Esse questionamento do caráter sacro da vida conduz também a uma confirmação paradoxal de uma das crenças mais arcaicas e duradouras do debate sobre os processos de formação nas sociedades ocidentais: a plasticidade da natureza humana. Nessa direção, um dos inúmeros benefícios obtidos pela filosofia da educação e creditado ao avanço das novas ciências da vida consiste na descoberta da chamada plasticidade neuronal, denominação genérica da propriedade do sistema nervoso que permite o desenvolvimento de alterações estruturais em resposta às condições mutantes e estímulos repetidos. As neurociências têm demonstrado que os neurônios se modificam durante toda a vida, o que pode ocorrer tanto através da eliminação de neurônios que não estão sendo utilizados, como pela alteração no dinamismo morfológico e funcional dos que estão em uso $^{3}$. O mais curioso é que, nessas análises, o cérebro passou a ser considerado uma espécie de obra de arte em constante construção, admitindo-se inclusive que, em períodos regulares, ele pode realizar o desligamento intencional de alguns neurônios a fim dar espaço para que outros possam se desenvolver de forma mais eficiente.

Essas verdadeiras "podas neuronais" (SOARES; ANDRADE; GOULART, 2012, p. 69-70) recebe múltiplas influências do meio, afeta a subjetividade e nos torna indivíduos em permanente mutação. No campo educacional, a repercussão desse debate vem deslocando a clássica disputa filosófico-cognitiva entre qualidades inatas versus qualidades adquiridas por experiências sociais, o que também contribui para ressignificar globalmente a reflexão antropológica sobre os processos de aprendizagem.

Mas o fato é que a própria diferenciação entre plasticidade neuronal e plasticidade comportamental tem sido considerada como meramente didática,

\footnotetext{
${ }^{3}$ Cada neurônio envolvido nesse processo procura aumentar seu vigor funcional, reduzindo a possibilidade de apoptose, uma espécie de suicídio que visa fortalecer as sinapses necessárias e a perda das consideradas como menos importantes, uma vez que não estejam em uso constante, pois apenas as sinapses que envolvem "neurônios competentes e ativos na rede" permanecem (SOARES; ANDRADE; GOULART, 2012, p. 69).
} 
pois, na verdade, elas seriam as faces de uma mesma moeda. O fenômeno da plasticidade aponta para a necessidade de se compreender o ser humano em todas as suas dimensões e relações. Uma reivindicação originariamente defendida pela filosofia da educação.

Nesse contexto, a pretensão específica dessa reflexão consiste em problematizar a retomada do debate sobre a plasticidade, tematizando alguns dos motivos que levaram a antropologia filosófica, em geral, e a pedagogia, em particular, a abandonar o tratamento crítico acerca dessa noção, admitindo que ela redimensiona o debate sobre o projeto humanista que, como sabemos, é indissociável da convocação antropocêntrica à dominação dos demais entes vivos, bem como daqueles entes que são considerados como não humanos ou inumanos. Com esse posicionamento, por meio de um salto (HEIDEGGER, 2013)4, atravessamos alguns aspectos da discussão sobre a biopolítica a fim de refletir sobre um possível devir-deficiente da pedagogia. Essa expressão visa ressaltar o papel das chamadas antropotécnicas nos processos de formação humana.

Para o filósofo alemão Peter Sloterdijk (2012a), as antropotécnicas são responsáveis por cultivar o humano, selecionando o que provém da multiplicidade ontológica da vida. Logo, não é casual que os mais duradouros domínios antropotécnicos da cultura ocidental, a medicina, o direito e a pedagogia sejam assombrados pela experiência da deficiência apreendida, quase sempre, como erro ou como enigma. Nos discursos filosófico-educacionais, a deficiência é representada como uma espécie de resto não apenas do humano, mas de uma corporeidade roubada ao Ser, e o deficiente como sendo o portador de uma plasticidade considerada ameaçadora, pois se assemelha aos outros humanos, sem, contudo, ser considerado como propriamente um igual.

A experiência da deficiência permite recolocar então um problema vital acerca da formação humana: com o que se parece um ser humano? A resposta

\footnotetext{
${ }^{4}$ No último parágrafo da seção final de seu ensaio póstumo Beiträge zur Philosophie - Vom Ereignis (Contribuições à Filosofia - Do acontecimento apropriativo - 1936/1946), Martin Heidegger articula os termos linguagem, seer e acontecimento apropriativo, visando uma desantropomorfização radical do homem enquanto ser vivo simplesmente dado. A linguagem desse acontecimento exige um salto (Sprung) em relação à atitude do pensamento representativo, indicando um novo caminho de pensamento.
} 
o devir-deficiente da pedagogia: notas para uma antropologia filosófico-educacional da plasticidade

exige lembrar que, no pensamento metafísico, sem aparência não há ontologia pensável, o que, por sua vez, exige a postulação de modelos eidéticos que objetivam plasmar um paradigma arquetípico acerca do sentido da humanidade. Assim, em Humanismo e teologia, Werner Jaeger (1964, p. 79) assinala que o núcleo central de todo humanismo é gerar ou regenerar um homem já nascido deficiente, posto que sempre em risco de não conseguir se converter plenamente em um humano verdadeiro. O problema da morphosis expressaria simultaneamente o problema da pedagogia e do humanismo, pois o que chamamos educação não é outra coisa senão o esforço para domesticar as suas forças plásticas.

Esse processo, contudo, tem sido resguardado pelos arcanos de uma antropologia que oculta a centralidade das técnicas desdobradas com o objetivo de aperfeiçoar ou corrigir o próprio do humano. Daí a urgência de realizar uma ontologia crítica da deficiência, tomando como eixo central da reflexão o fenômeno da plasticidade.

\section{Virada antropotécnica, tensão vertical e formação humana}

A crítica da antropologia como elemento reitor do pensamento tornou-se uma espécie de senso cult da filosofia e da cosmologia pós-hegeliana, sintoma de uma fenomenologia que vem sedimentando seus estratos desde os primeiros anúncios da morte do homem (ROMANDINI, 2010). Desde então, a filosofia, em geral, e a filosofia da educação, em particular, tem procurado se desvencilhar da herança ontoteológica, contando com o anúncio de um pós-humanismo que se faz acompanhar, inclusive de um conjunto renovado de avatares, dentre os quais, destacam-se o cyborg e o animal.

Peter Sloterdijk (2002a) contribuiu para transpor esse debate para o centro da esfera pública midiatizada com a publicação de suas Regras para o parque humano, originalmente uma conferência desenhada como um comentário à Carta sobre o humanismo de Martin Heidegger ${ }^{5}$. Os efeitos explosivos dessa exposição não

\footnotetext{
${ }^{5}$ Peter Sloterdijk nasceu em 1947 em Karlsruhe, onde reside e ensina filosofia e técnica da mídia. No Brasil ainda é um autor pouco conhecido e estudado, principalmente no campo educacional.
} 
tardaram a se manifestar. Em um debate movido por ânimos irritadiços e controversos, Sloterdijk foi acusado de defender uma postura neo-eugenista ao cogitar a possibilidade de modificações técnicas visando o melhoramento genético do organismo humano. Menos de um ano depois, em outra conferência, dessa vez, intitulada O homem auto-operável, ele focalizou o tema da clonagem (SLOTERDIJK, 2011), defendendo, dessa vez, que o homem se tornou homem na medida em que se fez ao fazer técnicas de se fazer. A ideia articuladora dessas intervenções consiste em afirmar que qualquer crítica endereçada ao humanismo exige realizar uma análise da abertura biológica da espécie humana, a fim de ressaltar a ausência de uma natureza prefixada no e do homem, trazendo à tona um elemento comumente deixado à margem pela filosofia: a questão da técnica.

O pensamento contemporâneo tem privilegiado noções como trabalho, experiência e linguagem, enquanto Sloterdijk (2002b) propõe que o estudo das antropotécnicas se tornem o verdadeiro centro de problematização da antropologia filosófica. O seu argumento radicaliza o tema da diferença ontológica por meio de uma crítica sutil ao pensamento de Heidegger. Inicialmente, ele tematiza a noção de Dasein, considerada como ainda assobrada pelos efeitos antropocêntricos induzidos pelo hábito humanista de fixação do homem enquanto animal racional. No entanto, seu alvo é o próprio legado heideggeriano que apreende o homem como guardião ou pastor do Ser.

No pensamento de Heidegger (1987), a essência do homem depende de uma relação originária com o Ser. O homem é dotado de racionalidade, porém não é isso que define a sua essência manifesta na sua ek-sistência. A ek-sistência é a clareira (Lichtung) do Ser, o que significa que o homem é o único ente que tem consciência do Ser. Assim, enquanto pastor do Ser, o homem é o único ente capaz de fazer a guarda e se manter à escuta do apelo do Ser6. Essa é a resposta-recusa de Heidegger aos humanismos.

Uma de suas principais obras, Crítica da razão cínica, editada em 1983, só foi publicada entre nós em $2012 b$.

${ }^{6}$ Para Heidegger (1987), o ser-aí (Dasein), tem o aí como clareira e, de certo modo, ele próprio é a clareira. As plantas e os animais estariam mergulhados no ambiente, mas nunca "inseridos na clareira do ser" (p. 49), pois falta-lhes a linguagem. A "linguagem é o advento iluminador-velador 
Sloterdijk (2002a, p. 28), por sua vez, propõe um novo esclarecimento do tema da clareira na medida em que essa noção não permitiria explicitar as condições implicadas na escuta paciente e silenciosa ao apelo do Ser, omitindo o fato dos seres humanos falantes logo que começam a viver junto se ligarem não só às "casas da linguagem", como defende Heidegger, mas também às "casas construídas", o que os torna "não apenas resguardados por sua linguagem, mas também domesticados por suas habitações".

A clareira indicaria uma abertura em relação à lógica que impera em nossas casas, desvelando a racionalidade que sustenta nossos modos de construir e habitar as casas em que vivemos, bem como o modo como praticamos nossas fazeres educativos. Sloterdijk (2002a, p. 38) quer, portanto, nos fazer ver um processo de "domesticação do Ser", apresentando a clareira como "um campo de batalha e um lugar de decisão e seleção". Essa decisão e seleção pressupõem atos acerca do tipo particular de construtores de casas que chegarão ao comando do próprio modo de habitar na clareira. De fato, concede Sloterdijk, o homem não é um ser biológico recoberto com camadas de verniz cultural, mas uma vez pensado como guardião e pastor do Ser há que se esclarecer o que, nessa solicitação, obriga o homem a fazer para se autoproduzir enquanto tal.

A clareira torna-se então um locus privilegiado para observar as operações biopolíticas que agem sobre indivíduos e grupos, mostrando a domesticação como uma espécie de grande impensado da filosofia ocidental. Desse modo, a investigação antropotécnica assume como ponto de partida uma antropomonstruosa (SLOTERDIJK, 2002b, p. 82), onde se acolhe não mais os signos do divino ou do animal para a explicitação dos enigmas da formação humana. A análise é balizada por meio de pesquisas situadas no campo da biopalentologia e da zoologia contemporânea, que enfatizam a emergência de mudanças no corpo humano derivadas do uso de tecnologias específicas, o que permite delinear os quatro mecanismos das antropotécnicas básicas: o mecanismo insular, a supressão dos corpos ou desconexão, a neotenia e a transferência.

do próprio ser", é a "casa do Ser" (p. 58). Por isso, o homem, é o ente chamado para habitar na casa da linguagem e cuidar do Ser. 
O mecanismo insular diz respeito ao fato de um grupo de seres vivos se isolar e, então, adquirir um clima favorável ao cuidado dos seus membros. Nesse ambiente climatizado se produziria uma espécie de estufa onde a progenitora pode se tornar mãe e sua cria um infante. A desconexão refere-se, por sua vez, aos novos membros desse grupo que, aclimatados, podem então se descolar do contato com o meio circundante. A neotenia é o que permite incorporar novas habilidades e saberes no próprio fluxo genético da espécie, gerando o sujeito humano apreendido como o animal que nunca termina seu aprendizado. Por fim, a transferência ocorre quando os grupos humanos tentam transpor e traduzir suas experiências hostis em momentos significativos, dando origem às religiões e às grandes ondas migratórias, por meio das quais se lançando no espaço indivíduos e grupos buscam atingir outros mundos. Esses quatro mecanismos articulam a história do devir-humano-monstruoso como a história das suas errâncias.

\begin{abstract}
A errância caracteriza a forma mesma do movimento histórico da existência que [...] fazendo o seu caminho [específico] através do nãoespecífico - seja a partir do desejo de voltar para casa, seja no sonho de uma viagem infinita, sem chegada. Vagando desde a errância, orientada ou não orientada, nenhuma pátria pode ser considerada como a situação fundamental do homem e os erros na sua própria auto-compreensão se constituem, de fato, em uma regra (SLOTERDIJK, 2002b, p. 78).
\end{abstract}

Na obra Você tem que mudar sua vida, Sloterdijk (2012) discute o principal desdobramento ético-político da sua virada antropotécnica: o processo de autoprodução do homem através dos exercícios. Toda vida humana, afirma ele, é delineada como uma vida de exercícios, e os exercícios são realizados porque o homem é atravessado por uma espécie de tensão vertical. Essa noção pretende explicar o fato das culturas serem edificadas a partir de diferenças norteadoras: sagrado versus profano, nobre versus comum, conhecimento versus ignorância, etc. Enquanto um desses polos se torna um atrativo, o outro ganha a função de grandeza negativa, constituindo nesse processo as identidades e constrangendo as diferenças, pois a tensão produzida entre grandezas superiores e inferiores exerce uma influência orientadora sobre os indivíduos.

A tensão resultante define as decisões existenciais e delimita o tipo de esforço que precisa ser realizado a fim de que os indivíduos ou mesmo grupos 
o devir-deficiente da pedagogia: notas para uma antropologia filosófico-educacional da plasticidade

possam superar um determinado estado em favor de uma superioridade ainda não alcançada, mas idealizada. Esse trabalho exige, quase sempre, algum tipo de postura ascética necessária para garantir as energias que visam aproximar os sujeitos do ideal visado. Com essa compreensão, Franz Brüseke (2011, p. 165) ressalta que Sloterdijk pretende "nada menos do que elaborar as bases de uma nova antropologia material na base de uma antropotecnologia geral" à luz de uma ascetologia destranscendentalizada.

Uma antropologia que faz do disciplinamento a causa de diferenciações que lançam os homens na busca de ideais improváveis. O ser humano viveria na e da repetição, dando forma e conteúdo à própria vida através de um ritualismo mais ou menos consciente. Por isso, a definição do humano não precisa evocar a ideia de uma excepcionalidade antropológica, enfatizando antes uma repetitividade na criatividade, através de uma pedagogia arcaica destinada a influenciar, in statu nascendi, crianças e jovens por meio de exercícios repetitivos. Esse processo exige a escola, um projeto pedagógico extremamente complexo, cuja origem remonta aos romanos que qualificaram como cultos todos aqueles indivíduos que optavam pelos livros em detrimento do estádio.

Importa dizer que os exercícios não seriam um capítulo na história da pedagogia, mas sua própria razão de ser ontológica. A escola, nesse contexto, funciona como um tipo particular de "sistema imunológico", fazendo o homem surgir de uma "pequena minoria de extremistas ascéticos" (SLOTERDIJK, 2012, p. 350-351). Mas, para executar essa tarefa, a escola deve controlar suas "aberturas sensoriais" e seus "nexos comunicativos", uma vez que a vida escolarizada depende de uma desaffektion conduzida por um conjunto de práticas de conversação interna (autoexortação, autoexame, autoavaliação) responsáveis por fazer surgir um observador mental, segundo os critérios definidos pelas tradições escolares sob a orientação de um mestre qualificado.

O mais interessante é que a virada antropotécnica compreende os processos de formação do humano como sendo inseparáveis da análise do tratamento da deficiência, colocando em xeque um dos traços característicos da 
pedagogia: o entendimento do humano como aquilo que se manifesta apenas em ato, ou seja, como um ente que é porque um agir específico se ocupou do aperfeiçoamento da sua natureza. A impossibilidade de aperfeiçoamento, exemplificada pelos sujeitos deficientes, permite que a pedagogia se volte para o seu fazer como uma combinatória aberta no e do possível, recuperando, no mesmo movimento, uma ideia seminal do nosso vocabulário filosófico: a plasticidade. Como sinaliza o texto clássico de Werner Jaeger (2010), a pedagogia filosófica ocidental surgiu como uma atividade antropoplástica. $\mathrm{O}$ questionamento ontológico da deficiência permite então retomar criticamente essa visão no contexto da biopolítica contemporânea.

\section{A lição dos deficientes para além da finitude e da biopolítica}

Na perspectiva antropotécnica, a educação configura-se como um saber e uma práxis onde subsiste um modelo ontológico autorreferente, no qual a deficiência historicamente tem operado como uma espécie de limite, isto é, como uma impossibilidade de expressar e atingir um modelo idealizado de ser humano. Esse modelo emerge atrelado à lógica pastoral que subsiste nos dispositivos de formação da subjetividade e que nos faz submeter e reencontrar em uma forma imposta e longínqua de identidade. Por isso, lembra Foucault (2003, p. 51-52), em toda cultura existem práticas que dizem respeito aos corpos, aos gestos, às regras sobre como se deve agir em relação a diferenças específicas sempre avaliadas em relação a um modelo dado. A tentativa da educação é construir o homem à imagem e semelhança desse modelo.

O simples fato de que, em uma cultura como a nossa, seja possível apelar para uma pluralidade de modelos não constitui, de fato, uma saída para o peso exercido pelas normalizações. A variedade e a diversidade de modelos identificatórios apenas tende a naturalizar o que é efetivo em uma dada realidade. Em outras palavras, todo modelo impede o devir, pois visa fixar a processualidade da vida e hierarquizar os modos de existência possíveis, sobretudo aqueles que emergem desacoplados de um modelo paradigmático considerado superior. Por essa razão, diz Sloterdijk (2012, p. 99), aqueles que não dispõem das habilidades 
o devir-deficiente da pedagogia: notas para uma antropologia filosófico-educacional da plasticidade

plenas do seu corpo, porque nasceram com alguma forma de deficiência, sabem melhor do que os outros o que está em jogo em um dado processo formativo. Os deficientes, ou os aleijados como ele prefere denominar, guardariam as lições mais inquietantes de nossas máximas pedagógicas.

Essas lições têm sido evitadas, pois questionam tanto a lógica da representação como a lógica das diferenças 7 . Nesse sentido, Sloterdijk recupera a história de Carl Hermann Unthan (1848-1929) que, tendo nascido sem os dois braços, buscou expandir suas capacidades descobrindo aos sete anos a possibilidade de usar seus pés para tocar violino. Unthan não só atingiu uma virtuosidade que o tornou conhecido internacionalmente, mas também foi reconhecido por outros músicos como Johann Strauss e Franz Liszt. O interesse de Sloterdijk pela biografia de Untham visa apontar nele o desejo não de ser visto ou tratado diferencialmente, mas de alcançar a mesma normalidade que seus colegas músicos viviam. Foi com esse projeto de vida que, mobilizado por um valor estético-musical específico, Untham se dedicou aos exercícios com uma concentração apenas comparável ao dos antigos ascetas.

Essa experiência, mais comum do que imaginamos, permite extrair da vida dos aleijados outra perspectiva do que significa formar-se como (e formar) um ser humano. Ao invés de projetar uma pedagogia sobre ou para os deficientes, trata-se de interrogar o que conceitualmente a pedagogia deve aos próprios deficientes que estuda. $\mathrm{O}$ argumento importa na medida em que à força de sempre ver o Mesmo no Outro, a pedagogia acaba por tomar o atalho que leva, no fim e no fundo, à captura das singularidades. Desse modo, a virada antropotécnica faz com que a pedagogia entre em relação com uma imagem não reconhecível do sujeito da educação, colocando a própria pedagogia em uma espécie de regime de variação, onde as teorias filosófico-educacionais são abordadas como versões das práticas e formas de vida consideradas deficientes. Com esse gesto, aparentemente

\footnotetext{
${ }^{7}$ A diferença exposta pelos deficientes aparece como uma ficção ruinosa que permite controlar o campo de visibilidade e discursividade estruturante das próprias teorias pedagógicas. A mera postulação de políticas voltadas à inclusão amistosa das diferenças não é considerada condição suficiente para conjurar os perigos que se inscrevem no corpo deficiente, apreendido, ele mesmo, como um espaço de produção de subjetivações heterotópicas e detonador de importantes crises de sentido da educação.
} 
banal, mas não óbvio, a virada antropotécnica coloca um desafio extraordinário para a pedagogia, obrigando-a a enxergar nas formas de vida deficientes uma alteridade que é capaz de colidir com os fundamentos identitários e antropocêntricos do projeto humanista. A deficiência faria ecoar o outro lado de nosso pensamento pedagógico, ou seja, aquele lado que enxergamos como seu lado menor, marginal, excepcional: o lado dos perdedores da história antropotécnica da educação.

O mais estranho, contudo, é que esse eco se fez ouvir primeiro do lado das chamadas ciências da vida, pois foi nesse âmbito que as disfunções, as lesões e os acidentes foram apreendidos como elementos centrais para a compreensão de fenômenos que envolvem os processos de aprendizagem. Catherine Malabou (2004), por exemplo, faz parte do número restrito de filósofos que têm retomado, de modo sistemático, noções biológicas com o objetivo explícito de problematizar nossa compreensão do humano.

Um dos motivos apontados por Malabou para esse distanciamento entre a filosofia e as ciências da vida residiria também na difusão da analítica do ser-aí (Dasein) heideggeriana, a qual teria contribuído para a reificação do postulado da diferença ontológica entre vida e existência, desdobrando uma distinção radical entre o que é finito e o que é vivente com prejuízo para a elucidação das questões ontológicas.

No entanto, diferentemente dos realistas especulativos com quem tem dialogado, Catherine Malabou não defende um "depois da finitude" (MEILLASSOUX, 2015), procurando apenas pensar a finitude por outros meios, mobilizando para isso uma crítica da razão neurobiológica, filtrando certos usos filosóficos da biopolítica apresentada apenas como forma de instrumentalização da vida. Para tanto, ela desloca o debate para situações em que a vida deixa de estar fixada ao pressuposto de que a todo ser humano deve corresponder um rosto, privilegiando contextos em que a vida humana transborda as noções de indivíduo como forma de romper as práticas de classificação discriminativa dos viventes pela busca de similitudes. $\mathrm{O}$ argumento é que que, na atualidade, tanto o 
o devir-deficiente da pedagogia: notas para uma antropologia filosófico-educacional da plasticidade

vivo como o não vivo estão submetidos a um grau equivalente de manipulação das suas estruturas, colocados na posição de recurso disponível. Mas esse diagnóstico não desemboca na defesa de que todo o real foi investido pela tecnociência.

Ao contrário, a dispersão ontológica da vida, sua indeterminação radical também é o que permite resistir à biopolítica. O termo dispersão significando aqui duas coisas: primeiro, que certos traços da vida não correspondem necessariamente a certos órgãos, morfologias ou funções; segundo, que os seres viventes são atravessados por técnicas que os reorganizam permanentemente (ROSA, 2014, p. 361), o que implica redimensionar o tratamento filosófico da relação ontológica entre vida e técnica. A finalidade é mostrar as articulações contingentes das estratificações ontológicas e redimensionar a distinção praxis/techné no processo mesmo de formação do humano.

Nessa direção, Malabou (2004) recupera alguns conceitos que foram secundarizados a exemplo da noção de plasticidade. Essa noção, segundo ela, seria capaz de recolocar no horizonte da filosofia contemporânea outro caminho de esclarecimento das questões biopolíticas, através do reconhecimento da dívida que liga o humano aos mais variados aparatos técnicos, os quais são apreendidos como um conjunto de exercícios que, cristalizando um certo hábito e um certo uso, permite dar forma a uma vida que se relaciona tão profundamente à sua forma a ponto de dela resultar inseparável.

A aproximação entre as reflexões de Malabou e a virada antropotécnica de Sloterdijk permite perceber que a técnica, ou antropotécnica, expressa uma regra incorporada e exercitada, que parece se confundir com a própria vida. Uma espécie de forma vivendi do sujeito ${ }^{8}$. O perigo, portanto, não é que a técnica se expanda às custas do vivo, mas a plasticidade intrínseca ao movimento mesmo da

\footnotetext{
${ }^{8}$ Em Altíssima pobreza: regras monásticas e forma de vida, Giorgio Agamben (2011) recupera e discute o sintagma forma vitae usado nos monastérios franciscanos. Os monges franciscanos foram combatidos precisamente porque reivindicavam um uso das coisas que separava uso e propriedade, identificando o uso com uma consumação dos objetos essenciais à vida dos padres, como comida ou roupa. O ser das coisas consumíveis coincidiria com sua transformação não sendo, portanto, redutível a uma propriedade. Em outras palavras, o uso seria sempre in fieri, isto é, consistiria efetivamente no seu devir.
} 
vida. O problema fundamental está relacionado com a catástrofe potencial associada ao processo de aparição de uma forma ontológica qualquer. Todo aparecer do vivente humano, ou seja, o fato irreparável de que esse ente precisa nascer para além do mero fato biológico, exige um agenciamento técnico que obriga quem chega a encontrar uma forma que lhe seja própria, e, ao mesmo tempo, reconhecível pelos demais. Essa forma gerada com e por antropotécnicas emerge por adição ou por subtração de determinadas qualidades diferencialmente valoradas no interior de uma cultura e de um tempo histórico dado.

O papel da pedagogia, nesse aspecto, permanece paradigmático, pois, sendo projetada para tratar de um agregado obscuro de males, ela agiria como uma espécie de medicina metafísica. Ao contrário da medicina que trata diretamente, no corpo, a ferida ou o cancro, e, em oposição às medicinas sagradas que tratam, no espírito, a possessão ou a acídia, a pedagogia visa extirpar, simultaneamente no corpo e na alma, os restos ontológicos ativos do processo de subtração ou adição biopolítica (por exemplo: a animalidade, a monstruosidade, a deficiência), seja acelerando e hipertrofiando, seja inibindo e sequestrando as próprias (im)potências humanas, a fim de fazer coincidir o que parece separado e estranho ou cindir o que parece animalesca e bestialmente conjugado.

Sabemos, contudo, que, em nossa atualidade, a separação tornou-se aquele tipo de atividade a ser combatida, tendo em vista que os mecanismos de separação e exclusão passaram a exigir um maior custo político e de procedimentos. A cultura do nosso tempo é não somente integradora, mas inventora de integrações e inclusões do que se faz indeterminado, o que não significa dizer que as exclusões deixaram de existir, embora tenham se tornado mais complexas e opacas. É nessa direção que a reflexão sobre a plasticidade pode oferecer um experimentum inusitado das bases antropológicas da educação e do tratamento da deficiência nos processos cultivados pela pedagogia.

\section{O devir-deficiente da pedagogia, os novos feridos e a Bildung como técnica plástica}


o devir-deficiente da pedagogia: notas para uma antropologia filosófico-educacional da plasticidade

Antoine Berman (2002) ao analisar, em um texto nascido clássico, as inflexões do tema da Bildung no contexto da modernidade, lembra que o termo permitiu articular diferentes compreensões de homem e de mundo, e, por essa razão não há dúvidas de que o termo carrega uma dimensão educativa, embora seu campo semântico seja complexo, incluindo dimensões como: imagem (Bild), imaginação (Einbildungskraft), desenvolvimento (Ausbildung), modelo (Vorbild) e cópia (Nachbild). Entretanto, ele também ressalta o fato do sentido da plasticidade (Bildsamkeit), intrinsecamente associado ao termo, ter se esvaziado, deixando de funcionar como uma categoria vital da reflexão filosófico-educacional. Ainda em meados do século XIX, o termo Bildung passou a enfatizar mais a ação prática e, sobretudo, o papel do formativo do trabalho produtivo, em consonância com os valores do progresso. $\mathrm{O}$ argumento conheceu desdobramentos na filosofia hegeliana e no pensamento marxiano. Mas, foi na obra de Goethe, Os anos de viagem de Wilhelm Meister, que essa posição se revelou em toda a sua clareza ao mostrar como o protagonista, inscrevendo-se em um círculo concreto de tarefas, se esforça no exercício de uma atividade determinada, para, ao final dessa experiência, se autodescobrir em meio aos encargos concretos da sua vida.

Nesse contexto, Berman (2007) nos faz notar uma referência direta à figura da viagem, cuja essência consistiria em lançar o protagonista no movimento de tornar-se outro de si mesmos. A viagem denotaria o encontro com a experiência da alteridade, deixando evidente nesse tour formador a natureza circular, ao mesmo tempo, cíclica e alternante do processo de Bildung, um lançar-se-além-desi-para-chegar-a-si, vivenciada como certa provação do estrangeiro, mas também como tradução do estranho.

Esse dinamismo da Bildung permite mostrar, para além da pluralidade dos seus significados, que o termo se configura, ele mesmo, de maneira plástica. Assim, os anos de aprendizagem de Wilhelm Meister permitem vislumbrar o ato mestre de toda pedagogia: o esforço na aprendizagem da formação de si, o que não é possível sem a virtude da plasticidade, sem uma maleabilidade formativa inerente ao próprio homem. A plasticidade encarnaria uma propriedade 
considerada distintiva do humano: a perfectibilidade pensada não como o poder de se tornar perfeito, mas enquanto capacidade de se auto aperfeiçoar, pois somente o imperfeito seria perfectível.

Com esse entendimento, os filósofos modernos vislumbraram na perfectibilidade o próprio da humanidade, uma qualidade tão específica a ponto de servir como parâmetro de distinção entre o homem e o animal (GOLDSCHMIDT, 1983). A faculdade de se (auto) aperfeiçoar residiria tanto na espécie como no indivíduo, indicando um processo de adaptação crescente rumo ao ideal potencial associado aos princípios da liberdade e autonomia. Na construção filosófica do humanismo, a noção de plasticidade passou a encarnar as virtualidades da natureza humana e a crença no seu aperfeiçoamento ${ }^{9}$.

Nesse âmbito, fomos inicialmente tentados a aproximar a noção de plasticidade daquela disposição que Nietzsche apontava como sendo capaz de fazer o homem, nesse caso ele mesmo, se tornar capaz de dar à luz centauros. Contudo, curiosamente, não é Nietzsche que os pensadores contemporâneos, preocupados com as questões ontológicas, têm buscado apoio para repensar criticamente a noção de plasticidade, e, sim, Hegel.

Assim, em O futuro de Hegel: plasticidade, temporalidade, dialética, Malabou (2013, p. 05) defende a plasticidade como a "'instância' que dá forma ao futuro e ao tempo na filosofia de Hegel". Partindo de uma ideia aparentemente acidental da filosofia hegeliana, ela nos oferece uma nova perspectiva sobre temas como subjetividade, razão e liberdade. A plasticidade é ressignificada como uma qualidade responsável pela singularização do sujeito, responsável por transformar a natureza em liberdade.

Na realidade, Homem, Deus, Filosofia, longe de serem sujeitos préconstituídos, se revelam como os lugares onde a subjetividade se constitui, as instâncias plásticas, onde os três grandes momentos da autodeterminação: o grego, o moderno e aquele do saber absoluto, se dão a forma de momentos, quer dizer, criam sua temporalidade especifica. Portanto, o conceito de "estágio" perde seu conteúdo evolutivo para

\footnotetext{
${ }^{9}$ A noção de plasticidade funcionou como uma forma de "transporte" nos processos de tradução da tópica renascentista da dignitas hominis, edificando uma visão otimista acerca da formação humana não predeterminada por qualquer incapacidade necessária restritiva (KAUSS, 2002).
} 
o devir-deficiente da pedagogia: notas para uma antropologia filosófico-educacional da plasticidade

designar então um corte - a operação de corte - na autoformação do tempo (MALABOU, 2013, p. 36).

Mais especificamente, Malabou (2013, p. 05) defende que, na filosofia de Hegel, tempo e futuro aparecem como "envolvidos mutuamente em um processo dialógico governado pela plasticidade". A articulação entre temporalidade, plasticidade e dialética visa destacar uma estrutura antecipatória, interior à própria subjetividade.

Para distinguir esta estrutura do futuro, vamos chamar esta estrutura 'ver (o que é) que vem' (le 'voir venir'), obedecendo a injunção de Hegel de filosofar no próprio idioma. 'Voir venir' em francês significa esperar, embora, como é prudente, observando como os eventos estão se desenvolvendo. Mas também sugere que as intenções e os planos das outras pessoas devem ser sondados e imaginados. É uma expressão que pode referir-se ao mesmo tempo ao estado de 'estar certo do que vem' ('être sûr de ce qui vient') e de 'não saber o que vai vir' ('ne pas savoir ce qui va venir'). É por esse motivo que o 'voir venir', 'ver (o que é) que vem', pode representar aquela ação recíproca, dentro da filosofia hegeliana, de necessidade teleológica e surpresa (MALABOU, 2013, p. 13).

Em outros termos, a noção de plasticidade permite a Malabou (2013, p. 26) explicitar o estatuto paradoxal de um índice do porvir, em relação ao qual o passado aparece revestido pela relativa estabilidade do "isso foi", o presente com a suposta referencialidade do "isso é" ou "está sendo" e o futuro, por natureza incerto e inverificável, seria a experiência que exige a conjuração proativa do que "está por vir".

A articulação do porvir colocaria em jogo o ato de observar determinados eventos a partir de um estado que envolve, de um lado, o saber "estar certo (do) que vem", mas, por outro, a percepção de que não se pode ainda "saber o que vai vir", mobilizando uma estrutura antecipatória no pensamento. $\mathrm{O}$ elemento central dessa estrutura é o hábito.

[...] a transição da natureza ao espírito [o hábito] não ocorre como uma superação, mas como uma reduplicação, um processo através do qual o espírito constitui a si mesmo em e como uma segunda natureza. Esta reduplicação reflexiva é em um certo sentido a 'fase do espelho' do espírito, na qual a primeira forma de sua identidade é constituída. O homem aparece como o avesso do animal, não como seu oposto. $\mathrm{O}$ conceito de 'segunda natureza', sinônimo de hábito, nos permite iluminar a grande originalidade da Antropologia (MALABOU, 2013, p. 26-27).

Com isso, o self antropológico, tal como descrito na filosofia hegeliana, é reinterpretado como o resultado de um processo de automodelação conjunta de corpo e alma, mediado pelos esforços do hábito. A repetição transformaria o 
aspecto corporal e a prática criaria o hábito, resultando na transformação do corpo em instrumento ativo de formação do sujeito. Disso decorre o interesse de Malabou (2013, p. 38) pela noção de individualidades plásticas, uma expressão de Hegel para designar o povo grego. Na Antiguidade, os gregos teriam emergido como autênticas individualidades plásticas na medida em que fizeram de si mesmos exemplos ou modelos formativos, dando forma ao espiritual em sua incorporação efetiva ao mobilizar uma atividade-de-forma. Os gregos abordaram suas vidas a partir de técnicas plásticas que funcionavam vinculadas a determinados modelos eidétivos que visavam induzir uma série de identificações miméticas, gerando e modificando hábitos, condutas e disposições (héxis).

Mas o que realmente importa a Malabou é mostrar a importância do hábito para as estruturas envolvidas na formação do humano, pois o hábito produziria uma abertura plástica onde vem se instalar o horizonte efetivo da Bildung, desvelando um sujeito que, embora condicionado, é pensado como estando aberto à sua própria plasticidade. Essa ideia repercute diretamente nas reflexões de Malabou sobre o papel das neurociências, contribuindo para gestar uma ontologia do acidente, a partir da qual é possível derivar uma reflexão filosófico-educacional renovada em torno da experiência da deficiência.

Nessa perspectiva, é importante lembrar que Malabou (2004, p. 12) se debruça sobre diversas pesquisas sobre a plasticidade neuronal a fim de enfatizar dois sentidos fundamentais do termo plástico: tomar forma e dar forma. A intenção explícita é criticar o uso "desviado" do termo plasticidade, através do seu suposto sinônimo: a noção de flexibilidade. A ênfase na flexibilidade amputaria, segundo ela, a plasticidade de sua dimensão inventiva: o aspecto do criar e dar formar, retendo apenas o tomar forma, caracterizado pela forma imposta. A flexibilidade seria uma forma reconhecível e identificável da plasticidade, um avatar ideológico encarnado na lógica que nos impulsiona para o mundo das representações mercantis e empresariais. Sem negar que exista uma versão da plasticidade compatível com a lógica neoliberal, ela procura articular no próprio cérebro uma forma de resistência material ao espírito do capitalismo. 
Ora, nós não queremos essas meias-medidas, isso que Nietzsche chamava justamente uma lógica de doente, desesperante e sofredora. O que nos falta é a vida, quer dizer, a resistência. A resistência é o que nós queremos. Resistência à flexibilidade, a essa norma ideológica veiculada conscientemente ou não pelo discurso reducionista que modeliza e naturaliza o processo neuronal a fim de legitimar certo funcionamento social e político (MALABOU, 2004, p. 139).

A análise de Malabou (2012) nega epistêmica e politicamente o cérebro como uma entidade ontologicamente determinada, afirmando que a plasticidade é o seu modo próprio de existência. Mais radicalmente, a plasticidade seria responsável pela configuração da forma mesma do nosso mundo, denotando o princípio de instabilidade da vida, isto é, o seu devir. Nessa direção, suas reflexões passam a focalizar os efeitos provocados pela ação dos acidentes, explorando uma terceira significação da noção de plasticidade, para além do tomar e do dar formar: a possibilidade de deflagração ou explosão de toda forma, como quando nós fazemos referência aos explosivos plásticos. Para explicitar seu argumento, como Sloterdik ao evocar os aleijados, Malabou convoca a presença dos chamados novos feridos. São eles: os pacientes de Alzheimer, os pacientes com lesões cerebrais graves, enfim, todos aqueles que sofreram alguma forma de metamorfose súbita das suas identidades em decorrência de situações traumáticas.

Hoje, as vítimas de traumas sociopolíticos apresentam o mesmo perfil
das vítimas das catástrofes naturais (tsunamis, terremotos, inundações)
ou acidentes graves (acidentes domésticos sérios, explosões, incêndios).
Começamos uma nova época de violência política, em que a política tira
recursos da renúncia do sentido político da violência [...] Todos os
eventos traumatizantes tendem a neutralizar sua intenção e assumir a
falta de motivação propriamente dita dos incidentes do acaso,
característica essa que não pode ser interpretada. Hoje, o inimigo é a
hermenêutica. [...] Esse apagamento do sentido não só é perceptível nos
países em guerra, como está presente em toda parte, como nova face do
social que confirma uma patologia psíquica desconhecida, idêntica em
todos os casos e em todos os contextos, globalizada (MALABOU, 2007, p.
258-259).

Os novos feridos representam todos os indivíduos que passaram por uma extrema violência relacional (vítimas de guerras, de abuso sexual, etc.), aproximados intencionalmente com os sujeitos que sofreram algum tipo de lesão ou dano cerebral, a fim de mostrar uma nova economia do acidente, ou seja, uma forma de morte em vida onde o que sobrevive passa a ser totalmente outro, expondo a experiência de uma total ausência de sentido tematizada como sinal da 
contingência e da aleatoriedade da vida. Como modelo dessa experiência, Malabou (2014, p. 52) retoma o acidente provocado por uma barra de ferro que perfurou o crânio de Phineas Gage, um supervisor de construção de ferrovias, que viveu nos anos 1880 em Vermont, nos Estados Unidos. Enquanto preparava uma carga de pólvora para explodir uma pedra, Phineas socou inadvertidamente uma barra de aço, o que resultou em uma explosão que projetou uma barra com $2.5 \mathrm{~cm}$ de diâmetro e mais de um metro de comprimento contra o seu crânio. A barra entrou pelo lado esquerdo do seu rosto, destruiu o olho, atravessou a parte frontal do cérebro e saiu pelo topo do crânio, pelo lado oposto. Phineas perdeu a consciência e sofreu várias convulsões, mas se recuperou, voltou a falar e caminhar normalmente, sobrevivendo à lesão. No entanto, algum tempo depois, ele começou a apresentar mudanças surpreendentes na personalidade e no humor, tornando-se uma pessoa antissocial. O médico que o atendeu, John Harlow, entrevistou amigos de parentes, e escreveu dois artigos sobre sua história médica, que logo se tornaria um clássico nos manuaisde neurologia. Na segunda metade do século XX, o seu crânio foi recuperado por pesquisadores da Universidade de Harvard e, recentemente, um reconhecido neurobiologista, Antonio Damásio, utilizou os recursos da computação gráfica para calcular a trajetória da barra de aço pelo cérebro de Phineas. A localização da parte lesionada do cérebro permitiu identificar a causa dos déficits percebidos nos processos de decisão racional e de controle da emoção de Phineas, transformando o seu caso em um modelo precursor dos debates sobre o cérebro emocional (DAMÁSIO, 1996).

Esses e outros exemplos retirados por Malabou (2014) da casuística dos neurologistas visa problematizar os efeitos provocados pela invasão de um corpo estranho, uma forma de encontro radical com uma diferença capaz de provocar no sujeito uma espécie de ida sem retorno, uma Bildung sem possibilidade de afirmação do sujeito. Ela lembra que "poucas rupturas vasculares, mínimas em termos do seu tamanho e objetivo" podem alterar radicalmente a identidade, às vezes irreversivelmente" (p. 59). Os novos feridos não sofreriam apenas alterações pontuais, mas se tornariam novas pessoas colocando-nos de frente aos desafios 
o devir-deficiente da pedagogia: notas para uma antropologia filosófico-educacional da plasticidade

implicados na terceira forma de plasticidade. Trata-se de estilísticas da existência que nem sempre estamos dispostos a enfrentar uma vez que colocam em cena uma espécie de forma destruída.

Por essa razão, os acidentes em nossas reflexões ontológicas aparecem ao lado do monstro, do animal, do anormal e do próprio deficiente, posto que os acidentes destrutivos não fornecem lugar a um outro redimido, originando, a partir de um puro acaso, alguém estrangeiro a si mesmo. Apenas a literatura fantástica parece reservar um lugar para esse tipo de narração, uma vez que o imaginário ocidental não parece disposto a suportar rupturas completas com o curso da identidade. A metamorfose pode dar origem à novas formas, mas nunca a uma mudança radical de essência. Logo, fenômenos associados à plasticidade destrutiva, ao fazer aparecer uma espécie de alteridade alien, onde está ausente toda transcendência, alheia à redenção, têm sido denegados pela filosofia.

Do nosso ponto de vista, tudo se passa como se um acontecimento enquanto puro possível negativo parece não permitir ao sujeito da educação se reapropriar da experiência vivida, paralisando toda forma de messianismo pedagógico. A pedagogia é então confrontada com o limite dos projetos formativos sustentados pelas antropotécnicas pastorais, bordejando as forças da vida que desconstroem o que parecia indesconstruível aos olhos da antropologia filosófica que lhe fornece legitimidade: a capacidade de aperfeiçoamento permanente da natureza humana. Com isso, dá-se a ver o principal fantasma do humanismo metafísico: a diferença pura, o corpo que encarna uma instância de existência radicalmente outra, indicando uma mutação destrutiva aquém e além da transformação do corpo num cadáver, prova da finitude, mas uma transformação do corpo em um outro corpo no mesmo corpo. Desse modo, a plasticidade destrutiva contamina todo o campo de pensamento e atuação da pedagogia com o anúncio da fragilidade que todos os humanos compartilham inclusive com os paradigmas do cérebro e da Terra ${ }^{10}$.

10 Lembremos, de passagem, o caso mais radical de plasticidade destrutiva em relação à experiência subjetiva que vivenciamos atualmente: a questão da Terra. Na obra Há mundo por vir?, Viveiros de Castro e Déborah Danowski (2014) afirmam que a possibilidade de pensarmos 
Essa sombria boa nova vem nos lembrar que o mero fato de estarmos vivos nos torna vulneráveis. O acidente torna-se uma propriedade da vida, e a capacidade de se transformar sob o efeito da destruição um horizonte possível, uma estrutura imanente ao próprio modo de ser do vivente. Todo corpo pode ser impactado por uma exterioridade, mas o resultado desse impacto pode ser a expropriação das forças ou o aumento da sua capacidade de resistir. Contudo, o que importa é que sem a percepção dessa condição vulnerável, o indivíduo não pode desfrutar das suas próprias impotências. Esse tipo de compreensão contém implicações éticas e políticas, pois como afirma Agamben (2014, p. 73), nada afeta tanto o destino humano como o estranhamento das suas impotências.

Aquele que é separado do que pode fazer pode, porém, resistir ainda, pode ainda não fazer. Aquele que é separado da sua impotência perde, ao contrário, principalmente, a capacidade de resistir. E como é somente a ardente consciência de que não podemos ser que garante a verdade do que somos, assim é apenas a visão lúcida do que não podemos ou podemos não fazer que dá consistência ao nosso agir (AGAMBEN, 2014, p. 73).

Assim, a ontologia do acidente, descrita por Catherine Malabou (2013) aponta claramente para os limites das referências antropológicas da pedagogia, sobretudo no que se refere ao acontecimento da deficiência apreendida como uma forma de plasticidade que coloca em xeque nossos esforços para formar o humano sem a promessa de aperfeiçoamento. A experiência da deficiência deixa entrever os entraves inerentes a todo discurso afirmativo, toda tentativa inclusiva ou mesmo salvífica de lidar com as formas de vida que se apresentam como lugar de resistência aos esforços da pedagogia de garantir a perfectibilidade daqueles entes sobre os quais exerce sua intervenção. A deficiência expõe nosso ponto mais vulnerável, uma fragilidade ontológica cujos efeitos podem provocar transformações radicais não apenas nos novos feridos, mas em todos que entram em contato com essa experiência, para além dos limites fronteiriços das identidades e das diferenças. Em outros termos, os deficientes expõem a possibilidade mesma de um devir-deficiente da pedagogia que abarca a 
o devir-deficiente da pedagogia: notas para uma antropologia filosófico-educacional da plasticidade

precariedade e a contingência de nossa condição ontológica, mostrando como determinadas intervenções plásticas visam produzir a vida deficiente como uma vida precária, como uma vida permanentemente ameaçada.

Com isso, a vida deficiente fica exposta tanto aos processos de judicialização da vida como aos mecanismos de seguridade, assujeitadas às chamadas políticas de inclusão que operam, na concretude dos corpos deficientes, como políticas de formação diferenciada da subjetividade, reiterando, por essa via, que certas vidas são assimetricamente privadas do uso autônomo de suas próprias incapacidades. A defesa de um devir-deficiente da pedagogia visa deslocar o debate sobre as políticas de inclusão, realocando-as no fato de sermos todos, na verdade, uns mais que os outros (BUTLER, 2009, p. 14), vulneráveis em relação com o outro, interrompendo a pulsão de domínio antropocêntrica face às formasde-vida que sintomatizam o desejo de banimento ou de controle e reconhecendo que a deficiência é uma forma de plasticidade que restringe ou impossibilita o aperfeiçoamento e torna inoperante a virtus da perfectibilidade ${ }^{11}$.

Trata-se então de assumir a indecidibilidade da distinctio humana, sua potencialidade infinita, lembrando, no entanto, que a história da filosofia da educação não pode se fechar em uma afirmação gloriosa das diferenças, uma vez que a experiência da deficiência, pensada desde a ontologia do acidente, deixa entrever que a questão da formação passa também pela compreensão da vida como possibilidade catastrófica. $\mathrm{O}$ encobrimento dessa questão produz o esquecimento de que a deficiência, ela mesma, é o que permite arrancar o homem de si mesmo, através das mais variadas antropotécnicas.

Por isso, o devir-deficiente da pedagogia coloca o discurso filosóficoeducacional sobre a deficiência em risco constante de queda ao lembrar que no arco aberto pela deficiência estende-se a vacuidade de toda promessa apaziguadora de domesticação antropolítica do humano. Pensar a deficiência,

${ }^{11}$ Com efeito, o conceito de plasticidade faz eco à noção de normatividade tal como pensada por George Canguilhem enquanto adaptação às novas normas desdobradas pela doença, bem como à noção de precariedade presente no debate político da performatividade de Judith Butler. Mas, nos termos de Malabou (2009, p. 49), na nova subjetividade gerada após certos traumas cerebrais ou sociais, o desvio seria demasiado imenso, demasiado assimétrico, uma desmesura para nossa capacidade de pensamento. 
nesses termos, pressupõe uma criatividade a reconhecer. Uma ocasião propícia para a problematização dos restos metafísicos que perseguem a discussão sobre a natureza da natureza humana através de um verdadeiro experimentum plasticum que desvela o homem não como um ser disponível, mas como o lugar (topos) mesmo da disponibilidade errática ou enigmática do ser.

Historicamente, as pedagogias pastorais tentaram e permanecem tentando capturar essa disponibilidade ao inventar para o homem uma origem e um fim (telos) fantasmático. Essa situação não apenas desemboca nas figuras do laboratório ou do campo, faz do próprio humano um campo-laboratório em sentido próprio. Vale ressaltar que o dispositivo eugenista visa justamente "resolver" o problema da incompletude humana, dispositivo do qual a pedagogia é parte ativa. Como alerta de John Glad (2008, p. 13 Apud. ROSA, 2014, p. 317), "a genética moderna é, historicamente, um derivado da eugenia, não o contrário". Eugenia tem significado, desde as suas primeiras formulações gregas, ser "bemnascido", cabendo, portanto, à reflexão filosófica contemporânea e à própria filosofia da educação explicitar que "bom nascimento" significa que o homem nasce, que a técnica o ajuda a nascer como o que devém melhor.

Nesse sentido, a defesa de um devir-deficiente da pedagogia almeja, antes de tudo, suspender as narrativas dominantes sobre a deficiência, denunciando a escala gnóstica que insiste em dividir os seres viventes entre aqueles que pertencem a este mundo e aqueles que lhe são estranhos por portarem uma diferença considerada anômala, quer dizer, uma diferença incapaz de, por si mesma, garantir a perfectibilidade do humano, a fim de desabilitar a maquinaria que sustenta o papel modelar da formação humana, acolhendo nesse mesmo gesto a plasticidade infindável e indomável de quem chega, dos recém-chegados cujo irromper no mundo não pode nem deve ser limitado por uma habitabilidade imposta nas fronteiras policiadas de nossas práticas pedagógicas. Por isso, o devir deficiente da pedagogia assume como sua questão vital os modos como aprendemos a nos expor ao antropomonstruoso chegante, ao que vem para lá do 
o devir-deficiente da pedagogia: notas para uma antropologia filosófico-educacional da plasticidade

horizonte, da teleologia, das programações calculáveis, da previsão e da providência.

\section{Para não concluir: na origem era a deficiência...}

Assim, ao final desse percurso, espero ter deixado claro a centralidade do problema plástico como um caminho fértil de problematização das bases antropológicas que sustentam o debate sobre a formação humana, mostrando que deficiência expõe o fato irreparável de toda formação se configurar como um programa de operação plástica. Uma operação conduzida com a finalidade de intervir na equação substancialidade versus acidentalidade, uma equação fundamental nos debates sobre o cultivo antropoténico da natureza humana. Nesse cenário, nunca é demais repetir que existem vidas e comunidades humanas particular e violentamente expostas à condição de precariedade.

Esse fato reforça a importância de recuperar criticamente a noção de plasticidade. O caráter errático do tratamento filosófico-educacional dessa noção mostra a força dos arcanos gnósticos que ainda regem nossos sistemas de pensamento, os quais reiteram a busca por modelo ideais sobre o que significa ser um ser humano. Sinteticamente, eis alguns dos seus pressupostos: uma insatisfação com a situação humana; a valoração do mundo como um contexto hostil; e a crença de que o conhecimento é a única ferramenta para tornar o humano disponível ao seu próprio aperfeiçoamento. É por essa razão que a gnose foi considerada como a verdadeira tecnologia do Ser (ROMANDINI, 2010).

Como todo gnóstico, o educador moderno é também aquele que pensa que só pode agir na medida em que vive do seu saber. Esse educador insiste em esquecer que nessa vontade de saber também entra em jogo uma ontologia da operatividade, onde ser e agir se confundem e interagem a fim de legitimar ou ocultar as intervenções plásticas realizadas pela educação. O devir deficiente da pedagogia opera (n)a impossibilidade dessa ontologia, preferindo não reconstituir modelos totalizantes do humano. Com isso, obrigando a pedagogia se voltar reflexivamente para o seu próprio fazer, para o seu ofício apreendido como uma articulação contingente no e do possível. 
Entendida dessa forma, a pedagogia pode reivindicar outras tarefas no que se refere aos sujeitos da educação, e, principalmente com relação aos sujeitos deficientes, deixando de atuar apenas como dispositivo de controle da relação entre potencialidade e atualidade e tornando inoperante o dispositivo antropológico. Para tanto, ela precisa reconhecer que qualquer configuração ontológica, inclusive a deficiência, é apenas um efeito incidental e, às vezes, acidental da aplicação de antropotécnicas específicas.

A preocupação da pedagogia sempre foi o controle das estruturas plásticas inerentes à condição humana. Assumir seu devir-deficiente, quem sabe, pode ser o caminho para escutar outras lições, acolhendo o fato de que toda presença, aparição ou manifestação humana emerge como um modo de habitar na imperfeição, no inacabado, no indeterminado. Por isso, o devir-deficiente da pedagogia não está ligado a uma política de reparação do humano, mas ao cuidado mesmo de nossas deficiências ontológicas, extraindo da memória histórica os rastros deixados pelo desejo de uma perfeição imposta.

O devir-deficiente da pedagogia vem nos recordar, portanto, que toda identificação e consequentemente toda diferença permanece na ordem do improvável, um ponto de vista, um lugar que nunca se dá a ver, mas a partir do qual se pode ver ou não. Uma deficiência é, nessa medida, incapaz de se sustentar a si mesma. Ela não tem um referente, expressando antes uma ruína. A ruína é o que acontece primeiro, na origem (DERRIDA, 1990, p. 69), ela é, portanto, sem promessa de restauro, o que, para escândalo das antropologias filosóficas e da filosofia da educação, nunca ameaçou o surgimento de uma obra. Assim, a deficiência nunca "chega depois para abalar um monumento", ela não é sinal de uma arquitetura perdida, sendo antes aquilo que acontece nas margens de um primeiro olhar, um traço de memória a reconstruir. O estatuto frágil da deficiência expressa a abertura constitutiva de nossas formas de vida, a clareira vazia de um círculo que deixa ver sem mostrar. Um acidente, uma contingência que não visa mostrar nada, nem pretende ensinar nada, mas insiste nos elementos fragmentários e disparatados que perturbam os corpos que habitamos. A 
deficiência é um acontecimento que só existe circunscrito pelas linhas de força presentes em um dado contexto que ele mesmo subverte.

A deficiência é um modo de perda, de se perder daquela perfectibilidade que tem servido de substrato para o funcionamento ortopédico dos dispositivos antropotécnicos, sinalizando os rastros expostos desses dispositivos, aquilo que fica de fora, as feridas de um real idealizado por nossos padrões reguladoresnormativos. A experiência do poeta francês Joë Bousquet, evocada por Deleuze (2001), vítima de uma bomba na primeira guerra, paraplégico aos vinte e um anos, e que teria afirmado: "meu ferimento já existia antes de mim, nasci para encarnálo", suscita então uma última questão: é possível apreender, pedagogicamente, o alcance dessa proposição aparentemente absurda?

A julgar pelo interesse dos filósofos da educação nessa vida (PAGNI, 2015), a questão da deficiência já não é mais a da representação, nem a da inclusão, pois não se trata de recriar, desde a pedagogia, uma imagem real e verdadeira ou semelhante e verosímil do ser-deficiente. Antes, a questão é impulsionar uma reflexão, polvilhada de imaginação e não orientada por um princípio de verdade, que diga dos modos como acessamos a nós mesmos, lembrando que o si mesmo da deficiência é apenas uma ficção ruinosa que permite, enfim, dar a ver o que nunca se verá, quem somos nós, alargando assim o campo de visibilidade e nesse mesmo instante preenchendo o território da pedagogia com outras formas de vidas ao admitir a existência do que permanecerá irreconhecível, impossível de ser reconhecido como verdade. Uma reconversão antropotécnica da formação humana cujo alvo principal, talvez, seja um novo uso plástico dos corpos deficientes no campo da educação capaz de subverter, simultaneamente, os regimes política de representação, a produção de saber sobre os considerados anormais e os processos de subjetivação que tomam as identidades como o fim último da ação.

\section{Referências}

AGAMBEN, Giorgio. El reino y la gloria. Buenos Aires: Adriana Hidalgo, 2008. AGAMBEN, Giorgio. Altísima pobreza. Reglas monásticas y forma de vida. Buenos Aires: Adriana Hidalgo, 2011. 
AGAMBEN, Giorgio. Nudez. Belo Horizonte: Autêntica, 2014.

BERMAN, Antoine. Bildung et Bildungsroman. Le temps de la réflexion, v. 4, Paris: Gallimard, em 1995 (1 ed., 1984), e no Brasil, pela Editora da Universidade de Santa Catarina (EDUSC), em 2002, com o título A prova do estrangeiro.

BERMAN, Antoine. A Tradução e a Letra: Ou o Albergue do Longínquo. Rio de Janeiro: 7 Letras/PGET, 2007.

BUTLER, Judith. Vida precária. El poder del deulo y la violencia. Buenos Aires: Paidos, 2009.

BRÜSEK. Franz J. Uma vida de exercícios: a antropotécnica de Peter Sloterdijk. Revista Brasileira de Ciências Sociais. v.26, n.75 São Paulo Feb. 2011.

DAMÁSIO, António R. O erro de Descartes: emoção, razão e o cérebro humano. São Paulo: Companhia das Letras, 1996.

DANOWSKI, D.; VIVEIROS DE CASTRO, E. Há Mundo por vir? Ensaio sobre os medos e os fins. Desterro: Cultura e Barbárie: Instituto Socioambiental, 2014.

DELEUZE, Gilles. Lógica do sentido. São Paulo: Perspectiva, 2001.

DERRIDA, Jacques. Mémoires d'aveugh. L'autoportrait et autres mines, Ed. Reunion des Musées Nationaux: Paris, 1990.

EHRENBERG, Alain. O culto da performance. Da aventura empreendedora à depressão nervosa. Aparecida, SP: Ideias \& Letras, 2010.

FOUCAULT, Michel. “O cuidado com a verdade”. In: FOUCAULT, Michel. Ditos e escritos, Vol. IV. Rio de Janeiro: Forense Universitária, 2003.

GIORGI, Gabriel. Formas comuns. Animalidade, literatura, biopolítica. Rio de Janeiro: Rocco, 2016.

GOLDSCHMIDT, Victor. Anthropologie et politique dans le système de Rousseau. 2. ed. Paris: Librairie Philosophique J. Vrin, 1983.

HABERMAS, Jürgen. The future of human nature. Cambridge: Polity, 2003.

HEIDEGGER, Martin. Acontecimento Apropriativo. Rio de Janeiro: Forense Universitária, 2013.

HEIDEGGER, Martin. Carta Sobre o Humanismo. Rio de Janeiro: Tempo Brasileiro, 1987.

JAEGER, Werner. Paideia: los ideales de la cultura griega. México: Fundo de Cultura Econômica, 2010.

JAEGER, Werner. Humanismo y teologia. Madrid: Ediciones Rialp, 1964.

MALABOU, Catherine. Le Temps. Paris: Hatier, 2007.

MALABOU, Catherine. Que faire de notre cerveau? Paris: Bayard, 2004.

MALABOU, Catherine. The new wounded: from neuroses to brain damage. New York: Fordham University Press, 2012.

MALABOU, Catherine. El porvenir de Hegel. Plasticidad, temporalidade, dialéctica. Lanús: Editorial Palinodia; Ediciones La Cebra, 2013.

MALABOU, Catherine. Ontologia do acidente. Ensaio sobre a plasticidade destrutiva. Florianópolis: Cultura e Barbárie, 2014.

MEILLASSOUX, Quentin. Despues de la finitude. Ensayo sobre la necesidad de la contingencia. Buenos Aires: Caja Negra, 2015.

PAGNI, Pedro Ângelo. “Diferença, subjetivação e educação: um olhar outro sobre a inclusão escolar". In: Revista Pro-posições, v. 26, n. 1 (76), p. 87-103, jan./abr. 2015. 
PELBART, Peter. O avesso do niilismo. Cartografias do esgotamento. São Paulo: N-1 Edições, 2013.

PRECIADO, Beatriz. Testo Yonqui. Madrid: Espasa, 2008.

ROMANDINI, Fabián L. A comunidade dos espectros. I. Antropotecnia. Florianópolis: Cultura e Barbárie, 2010.

ROSA, Jorge Leandro. A ruptura articulatória dos seres: a propósito da exposição da vida à dispersão da sua ontologia. Revista Scientiæ Studia. v.12, n.2. São Paulo, abr./jun., 2014, p. 359-377.

ROSE, Nikolas. A política da própria vida: biomedicina, poder e subjetividade no século XXI. São Paulo: Paulus, 2013.

SLOTERDIJK, Peter. Has de cambiar tu vida. Sobre antropotécnica. Valencia: PreTextos, 2012a.

SLOTERDIJK, Peter. Crítica da razão cínica. São Paulo: Estação Liberdade, 2012b.

SLOTERDIJK, Peter. “El hombre auto-operable. Sobre las posiciones filosóficas de la tecnología genética actual". Sileno. n. 11, Madrid. 2011. Disponible en otra versión (El hombre operable): http://www.revistaartefacto.com.ar/pdf_notas/91.pdf.

SLOTERDIJK, Peter. Regras para o parque humano - uma resposta à carta de Heidegger sobre o humanismo. São Paulo: Estação Liberdade, 2002a.

SLOTERDIJK, Peter. La domestication de l'être: pour un éclaircissement de la clairière. Paris: Editions Mille et Une Nuits, 2002b.

SOARES, Edvaldo; ANDRADE, Paulo; GOULART, Flávia. “Neurociência e educação: memória e plasticidade". Revista Psicologia: Teoria e Pesquisa. Mai-Ago, 2012, v. 17, n. 2, pp. 51-82.

Recebido em: 28.05.2016

Aceito em: 12.06 .2016 